\title{
Für alle, die sich nichts mehr entgehen
} lassen wollen

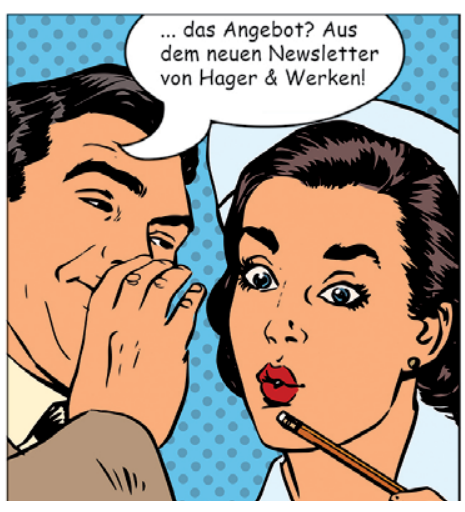

Hager \& Werken kann davor keinen Halt
Das Zeitalter, in dem digitale Medien zum täglichen Brot des Informationsflusses gehören ist schon lange erreicht.

Auch mehr machen und hat einen informativen und ansprechenden Newsletter erstellt. Abgestimmt auf die jeweiligen Abonnenten, wird in regelmäßigen Abständen über Aktionen, Neuheiten oder Veranstaltungen informiert.Anschaulich gestaltet mit Bildern, downloadbaren Flyern, Verlinkungen zu Videos, Gewinnspielteilnahmen und vielem mehr, lädt der neue Newsletter zum informativen Stöbern ein. Anmeldung zum Newsletter: www. hagerwerken.de

Nach einer Pressemitteilung der

Hager \& Werken GmbH \& Co. KG, Duisburg 